\title{
Calculation of Reaction Forces in the Boiler Supports Using the Method of Equivalent Stiffness of Membrane Wall
}

\author{
Josip Sertić, Dražan Kozak, and Ivan Samardžić \\ Mechanical Engineering Faculty in Slavonski Brod, Trg Ivane Brlić-Mažuranić 2, 35000 Slavonski Brod, Croatia \\ Correspondence should be addressed to Josip Sertić; josip.sertic@sfsb.hr
}

Received 29 August 2013; Accepted 29 December 2013; Published 15 May 2014

Academic Editors: S. Kou and K.-L. Ou

Copyright ( 2014 Josip Sertić et al. This is an open access article distributed under the Creative Commons Attribution License, which permits unrestricted use, distribution, and reproduction in any medium, provided the original work is properly cited.

\begin{abstract}
The values of reaction forces in the boiler supports are the basis for the dimensioning of bearing steel structure of steam boiler. In this paper, the application of the method of equivalent stiffness of membrane wall is proposed for the calculation of reaction forces. The method of equalizing displacement, as the method of homogenization of membrane wall stiffness, was applied. On the example of "Milano" boiler, using the finite element method, the calculation of reactions in the supports for the real geometry discretized by the shell finite element was made. The second calculation was performed with the assumption of ideal stiffness of membrane walls and the third using the method of equivalent stiffness of membrane wall. In the third case, the membrane walls are approximated by the equivalent orthotropic plate. The approximation of membrane wall stiffness is achieved using the elasticity matrix of equivalent orthotropic plate at the level of finite element. The obtained results were compared, and the advantages of using the method of equivalent stiffness of membrane wall for the calculation of reactions in the boiler supports were emphasized.
\end{abstract}

\section{Introduction}

Nowadays, the steam boilers of waste incineration power plants are made specifically according to the requirements of investors. Due to the location where the boiler will be set up, the amount and type of fuel to be burned in a given time, and technical parameters of produced steam, the production of steam boilers is mainly individual. This represents an exceptional effort for the designers. The pipes and sheet metal are the basic structural elements used for making boilers. Larger structural units called the membrane walls are obtained by welding these elements. The membrane walls make the basic structure of boiler and have a double function. The heat exchanger, that is, evaporator, is the primary function, and the secondary is transfer of loading. The steam boiler membrane walls are loaded by the pressure of working fluid (water/steam), their own mass, and the mass of other structural units that rely on the membrane walls, the mass of working fluid, the mass of insulation and refractory, and the fouling mass that is deposited during the combustion process. The loading is transferred across the membrane walls to the boiler supports and then to the bearing steel structure.
Since the water tube boilers are large structures consisting of a large number of pipes connected to the membrane walls, it is very difficult to accurately calculate the reactions in the supports. In practice, there are two approaches to calculate the reactions in the steam boiler supports. The first approach is based on the assumption that the membrane stiffness of the boiler membrane wall is very high, so the boiler is calculated as an ideal rigid body. The second approach takes into account the finite stiffness of the membrane walls using the finite element method. The discretization of real geometry of boiler (membrane walls) requires an extremely large number of finite elements, so this approach is rarely used, eventually for smaller boilers. Most often, the membrane wall stiffness is approximated by the equivalent stiffness of orthotropic plate/shell, which allows a multiple reduction of degrees of freedom of a numerical model.

It is difficult to find more detailed research papers on the topic of homogenization of steam boiler membrane wall. In 2012, Milošević-Mitić [1] with a group of authors proposed a procedure for calculating the strength of water tube boiler using the finite element of orthotropic plate. 
The homogenization of membrane wall stiffness is performed numerically, using the method of equalizing displacement.

When calculating the deflection of membrane walls due to the influence of underpressure/overpressure of flue gases, the equivalent wall thickness method is most commonly used in practice. The bending stiffness of membrane wall pipe is equal to the bending stiffness of equivalent wall thickness for the axis perpendicular to the longitudinal axis of membrane wall pipe, and the bending stiffness of membrane wall tape is equal to the bending stiffness of equivalent wall thickness for the axis parallel to the longitudinal axis of membrane wall pipe.

The steam boiler membrane wall represents a structurally orthotropic plate. The stiffened plates that are frequently used, both in building and in the processing/power plants, where it is necessary to achieve the optimal structural solution considering the mass of structure, also belong to this class of structures. The earliest research on the topic of stiffness of stiffened plates was most likely done by Huber [2-4]. His investigations were inspired by the lack of exact expressions for solving the problems of bending and buckling of stiffened structures by using the theory of homogeneous orthotropic plates. Similarly, Flügge [5] published the first paper on the topic of structurally stiffened shell in 1932, and 15 years later, so did van der Neut [6]. Over time, the understanding of the theory of deformation of structurally orthotropic plates and shells has progressed. The terms "equivalent stiffness" and "equivalent wall thickness" became the basis for the analysis of deformation of stiffened or structurally orthotropic plates/shells. Furthermore, Dale et al. [7] applied the equivalent stiffness in the research of buckling of pressure loaded sandwich plates. Smith et al. [8] proposed an improved formulation that takes into consideration the change of position of the neutral surface that is connected with the local interaction between the plate and stiffener. Pflüger [9], Gomza and Seide [10], and Libove and Hubka [11] applied in their research the method of equivalent stiffness and thickness of stiffened plate/shell. In the papers [12-14], the theory of symmetric sandwich plates, with the included transverse shear stiffness, is applied. In 1956, Huffington Jr. [15] analyzed the equivalent stiffness of orthogonally stiffened plate without the stiffener eccentricity. During the last fifty years, the equivalent plate or shell approach was still being used as a first approximation method [16-19]. For the experimental determination of elasticity constants, the method of testing the loaddeformation characteristics of repeating structural part of the structurally orthotropic plate was most commonly used [20]. In 1969, Soong [21-23] presented a derivation of the stiffness expressions for orthotropic cylinders based on a deformation energy approach. Throughout the following years, special attention was given to the interaction between the plate and stiffeners [24], for a different layout or grid of stiffeners [2527] and different combinations of loads. In 1995, Jaunky et al. $[28,29]$ presented a refined smeared-stiffener theory for grid-stiffened laminated-composite panels, based upon the work presented by Smith et al. [8]. Similarly, Wodesenbet presented an improved smeared-stiffener theory for gridstiffened laminated-composite cylinders in 2003.
It can be concluded that the current research is mainly based on two systematic analytical methods that take or do not take into account the transverse shear stiffness. First, there is a direct equilibrium-compatibility method. The first method uses equilibrium and compatibility in a direct manner for plates reinforced by stiffeners. The second one is called the basic-cell energy-equivalence method. The second method is based on defining the equivalence between the deformation energy of the basic repeating cell and the deformation energy of the equivalent orthotropic plate. This method is suitable for the determination of the members of elasticity matrix for grid-stiffened plates and sandwich plates.

Unlike the stiffened plates, a steam boiler membrane wall consists of a homogeneous plate with attached stiffeners. Therefore, the two mentioned methods are not entirely suitable for the determination of equivalent stiffness of membrane wall, that is, the equivalent elasticity constants. The process of homogenization of steam boiler membrane wall is presented in the papers [30-32]. The elasticity constants for the membrane and bending stiffness of membrane wall are determined theoretically, by equalizing the deformation of membrane wall with the deformation of equivalent orthotropic plate. In these papers, the transverse shear stiffness is not taken into consideration.

\section{Steam Boiler Membrane Wall as the Structurally Orthotropic Plate}

The steam boiler membrane wall can be approximated as the equivalent orthotropic plate, that is, the orthotropic plate, which will have the same elastic properties as the real membrane wall. Using Kirchhoff-Love theory of shells [33, 34 , the constitutive equations of equivalent orthotropic plate or shell can be written as follows:

$$
\sigma=\mathbf{D} \cdot \boldsymbol{\varepsilon}
$$

where $\boldsymbol{\sigma}$ is vector of section forces, D is matrix of elasticity, and $\boldsymbol{\varepsilon}$ is vector of deformation. According to [35], it can be said that the constitutive equations for the analysis of plates and shells are analog. The matrix expression (1) represents the six constituent equations of membrane wall as the structurally orthotropic plate or its equivalent orthotropic plate, which connect the section forces with the corresponding deformations

$$
\left[\begin{array}{c}
N_{1} \\
N_{2} \\
N_{12} \\
M_{1} \\
M_{2} \\
M_{12}
\end{array}\right]=\left[\begin{array}{cccccc}
A_{11} & A_{12} & 0 & 0 & 0 & 0 \\
& A_{22} & 0 & 0 & 0 & 0 \\
& & A_{33} & 0 & 0 & 0 \\
& & & D_{11} & D_{12} & 0 \\
& \text { sym. } & & & D_{22} & 0 \\
& & & & & D_{33}
\end{array}\right] \cdot\left[\begin{array}{c}
\varepsilon_{1} \\
\varepsilon_{2} \\
\varepsilon_{12} \\
\kappa_{1} \\
\kappa_{2} \\
2 \cdot \kappa_{12}
\end{array}\right] .
$$

$N_{1}, N_{2}$, and $N_{12}$ are the section forces (Figure 1), and, $M_{1}, M_{2}$ and $M_{12}$ are the section moments (Figure 2 ) in the membrane wall, that is, the equivalent orthotropic plate. $A_{11}, A_{12}, A_{22}$, and $A_{33}$ are the members of elasticity matrix for membrane loads, and $D_{11}, D_{12}, D_{22}$, and $D_{33}$ are the members of 


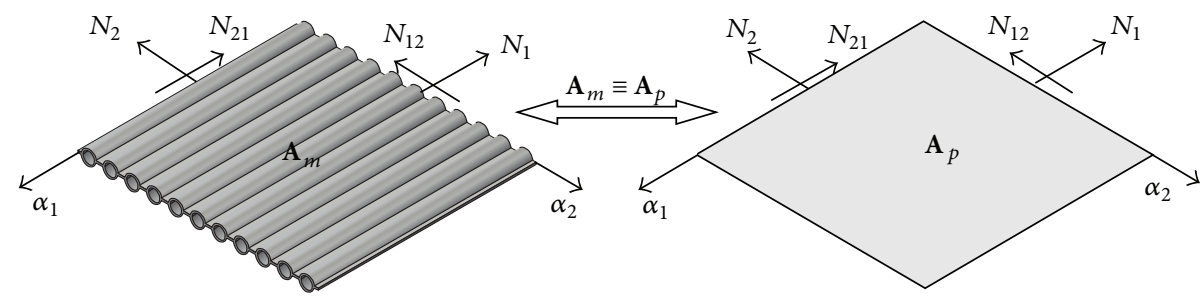

FiguRE 1: Section forces in the membrane wall, that is, the equivalent orthotropic plate, with the membrane stiffness of membrane wall $\mathbf{A}_{m}$ equivalent to the membrane stiffness of orthotropic plate $\mathbf{A}_{p}$.

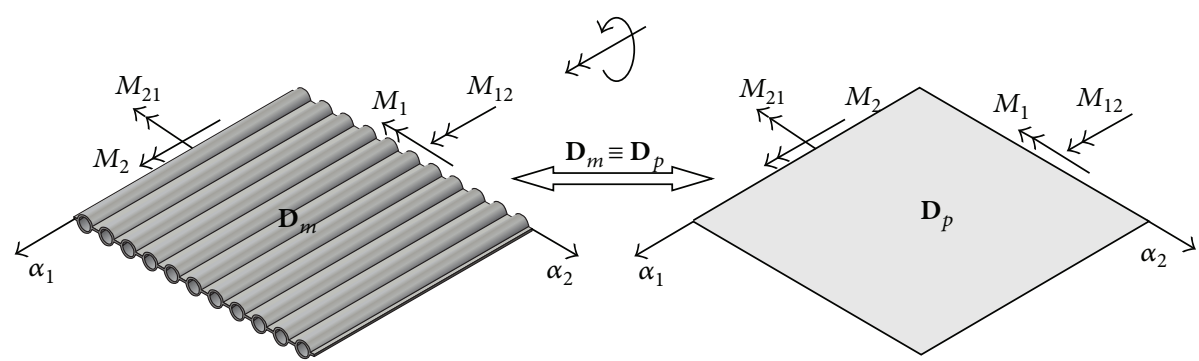

FIGURE 2: Section moments in the membrane wall, that is, the equivalent orthotropic plate, with the bending stiffness of membrane wall $\mathbf{D}_{m}$ equivalent to the bending stiffness of orthotropic plate $\mathbf{D}_{p}$.

elasticity matrix for bending loads of equivalent orthotropic plate. $\varepsilon_{1}, \varepsilon_{2}$, and $\varepsilon_{12}$ are the membrane deformations, and $\kappa_{1}$, $\kappa_{2}$, and $\kappa_{12}$ are the curvatures of neutral surface of structurally orthotropic plate, that is, the equivalent orthotropic plate.

The members of elasticity matrix referring to the membrane stiffness $[30,34]$ of membrane wall can be calculated using the following expressions:

$$
\begin{array}{ll}
A_{11}=\frac{E_{m, 1} \cdot h}{1-v_{m, 12} \cdot v_{m, 21}}, & A_{12}=\frac{E_{m, 2} \cdot h \cdot v_{m, 12}}{1-v_{m, 12} \cdot v_{m, 21}}, \\
A_{22}=\frac{E_{m, 2} \cdot h}{1-v_{m, 12} \cdot v_{m, 21}}, & A_{33}=G_{m, 12} \cdot h,
\end{array}
$$

where $E_{m, 1}$ is modulus of elasticity for the membrane stiffness in the direction of axis $\alpha_{1}$ (the axis parallel to the axis of pipe in the membrane wall), $E_{m, 2}$ is modulus of elasticity for the membrane stiffness in the direction of axis $\alpha_{2}$ (the axis perpendicular to the axis of pipe in the membrane wall), $v_{m, 12}$ is Poisson's ratio for the membrane stiffness in the direction of axis $\alpha_{1}, v_{m, 21}$ is Poisson's ratio for the membrane stiffness in the direction of axis $\alpha_{2}$, and $G_{m, 12}$ is shear modulus for the membrane stiffness. The members of elasticity matrix referring to the bending stiffness $[29,33]$ of membrane wall can be calculated using the following expressions:

$$
\begin{aligned}
& D_{11}=\frac{E_{b, 1} \cdot h^{3}}{12 \cdot\left(1-v_{b, 12} \cdot v_{b, 21}\right)}, \\
& D_{12}=\frac{E_{b, 2} \cdot h^{3} \cdot v_{b, 12}}{12 \cdot\left(1-v_{b, 12} \cdot v_{b, 21}\right)}, \\
& D_{22}=\frac{E_{b, 2} \cdot h^{3}}{12 \cdot\left(1-v_{b, 12} \cdot v_{b, 21}\right)}, \\
& D_{33}=\frac{G_{b, 12} \cdot h^{3}}{12},
\end{aligned}
$$

where the elasticity constants for the bending stiffness are indicated by index $b$. The expression for the wall thickness of equivalent orthotropic plate [30] can be obtained from the equality of moment of inertia of the cross-section of membrane wall, considering the plane perpendicular to the longitudinal axes of the membrane pipes (Figure 3), and the cross-section of equivalent orthotropic plate. Consider

$$
h=\sqrt{\frac{3 \cdot \pi}{16 \cdot D \cdot k} \cdot\left(D^{4}-(D-2 \cdot \delta)^{4}\right)+\frac{(k-D) \cdot t^{3}}{D \cdot k}} .
$$




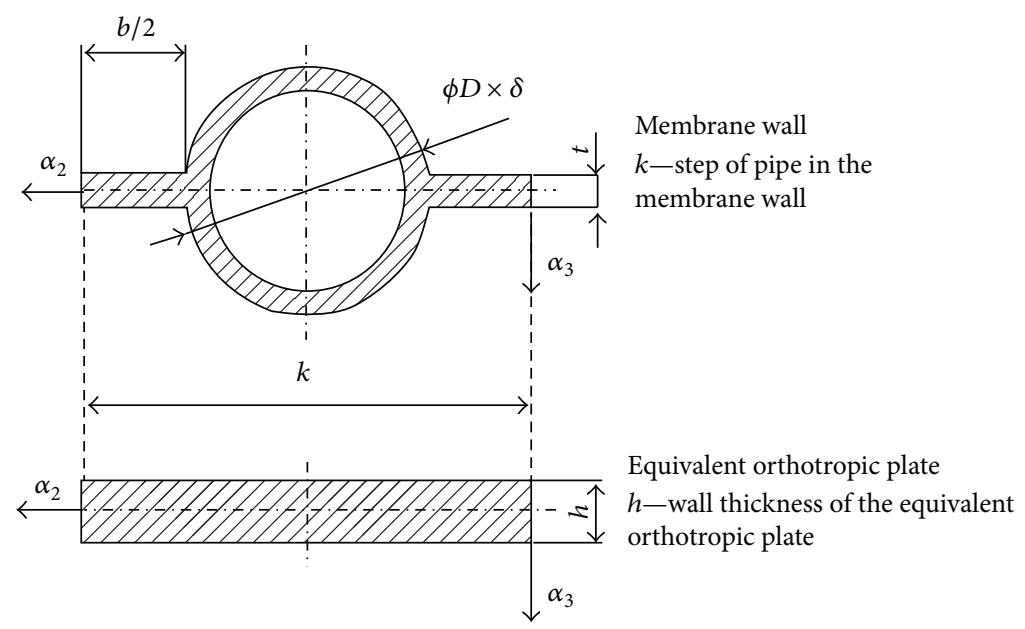

FIGURE 3: Geometry of cross-section of membrane wall and equivalent orthotropic plate.

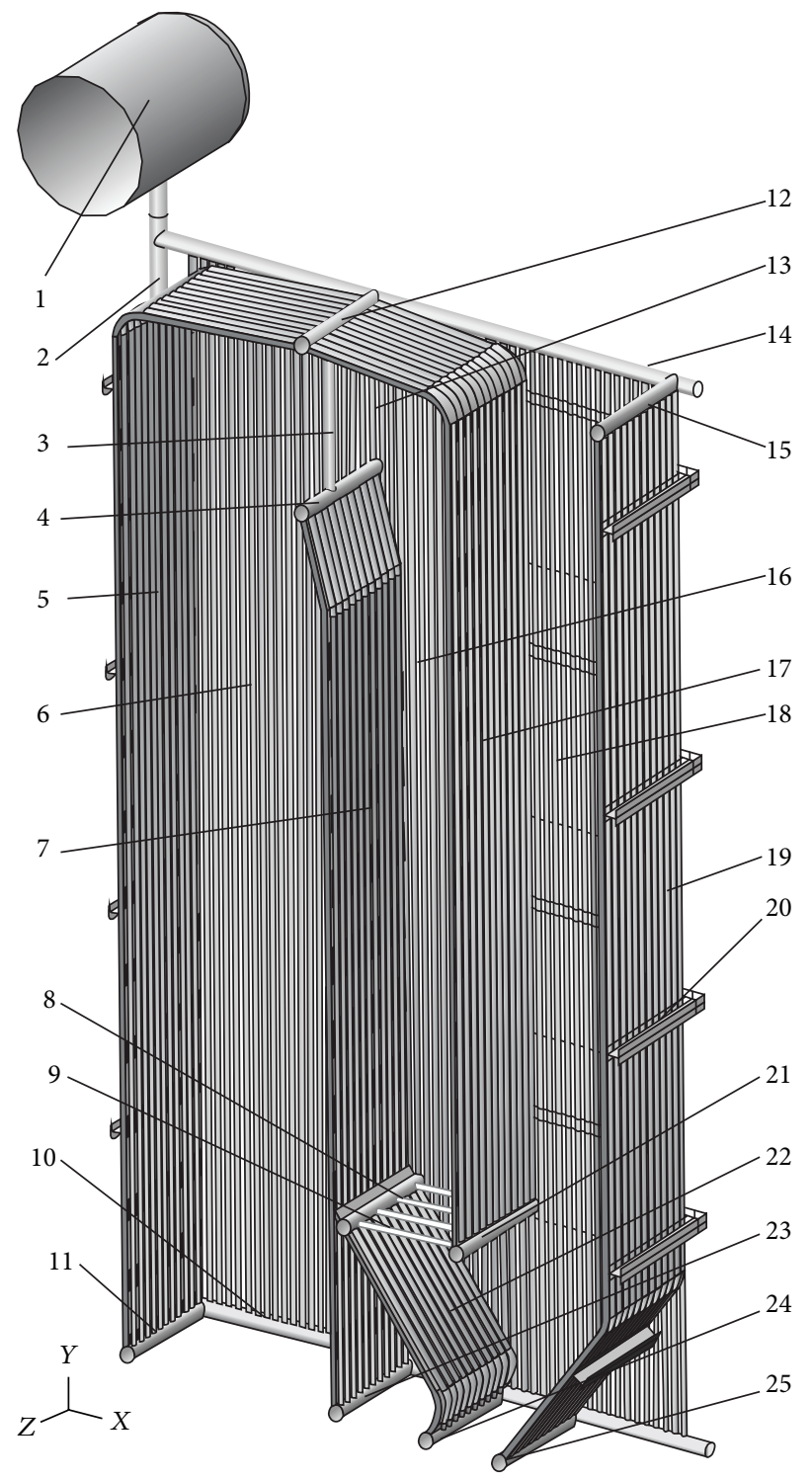

FIGURE 4: Real calculation geometry model. 


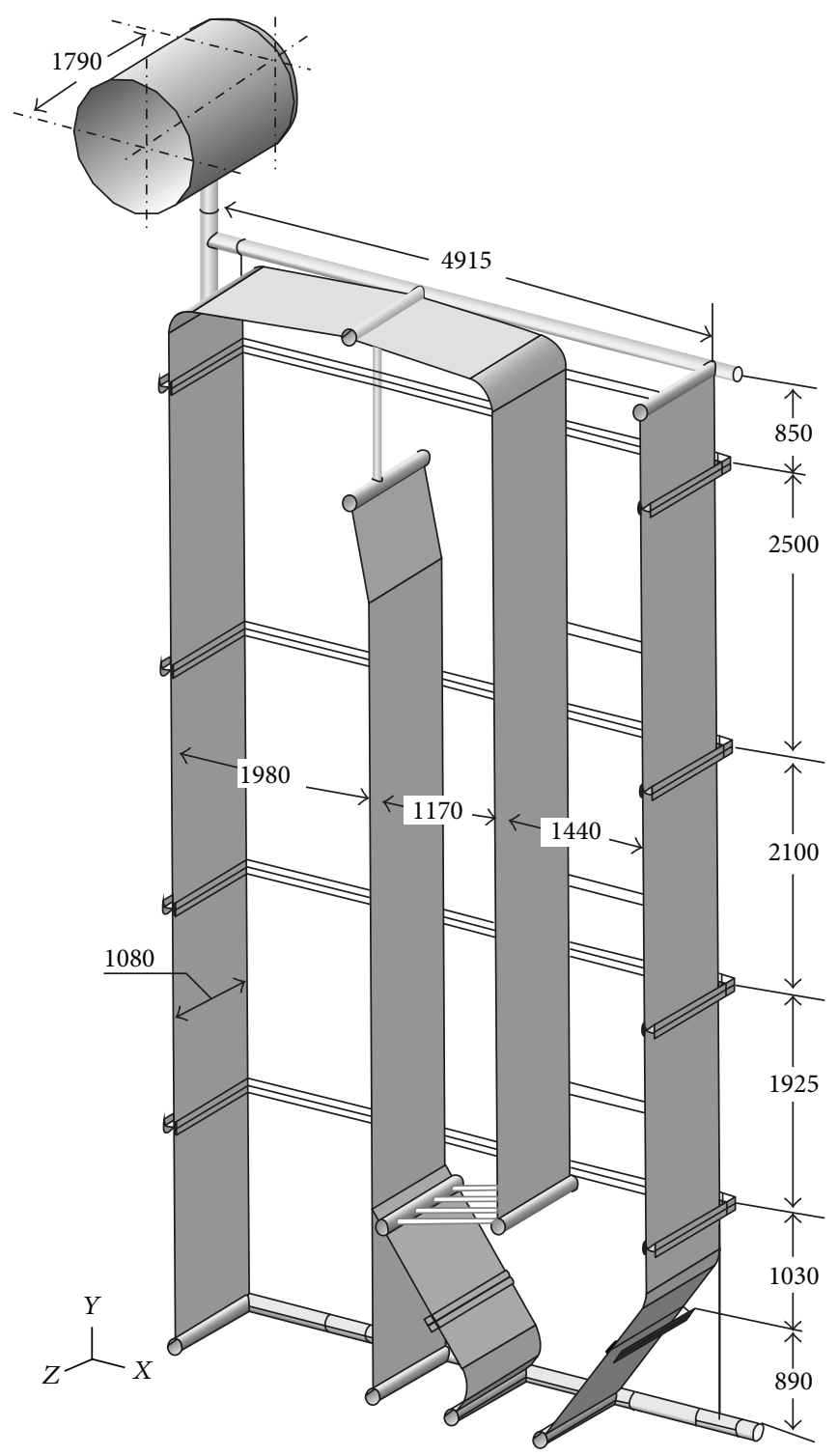

FIGURE 5: Calculation geometry model approximated as the equivalent orthotropic plate (dimensions are in $\mathrm{mm}$ ).

The elasticity constants of equivalent orthotropic plate, for the membrane stiffness, can be calculated using the analytical expressions suggested in the paper [31,32]. These expressions are obtained by equalizing the deformations of membrane wall and equivalent plate (thickness $h$ ), with the equivalent membrane load

$$
\begin{gathered}
E_{m, 1}=\frac{E}{k \cdot h}\left[\frac{\pi}{4} \cdot\left(D^{2}-(D-2 \cdot \delta)^{2}\right)+(k-D) \cdot t\right], \\
E_{m, 2}=\frac{k \cdot E}{h \cdot\left[3 \cdot(D / \delta-1)^{3} \cdot(\pi / 8-1 / \pi)+b / t\right]},
\end{gathered}
$$

$$
\begin{gathered}
G_{m, 12} \approx \frac{\sqrt{E_{m, 1} \cdot E_{m, 2}}}{2 \cdot\left(1+\sqrt{v_{m, 12} \cdot v_{m, 21}}\right)}, \\
v_{m, 21}=v_{m, 12} \cdot \frac{E_{m, 2}}{E_{m, 1}},
\end{gathered}
$$

where $E$ is modulus of elasticity, and $v_{m, 12}=\nu$ is Poisson's factor for the isotropic material of membrane wall. The expressions for the elasticity constants of equivalent orthotropic plate and for the bending stiffness of membrane wall are proposed in the paper [31, 32]. Same as for the membrane stiffness, these expressions are also obtained by equalizing 


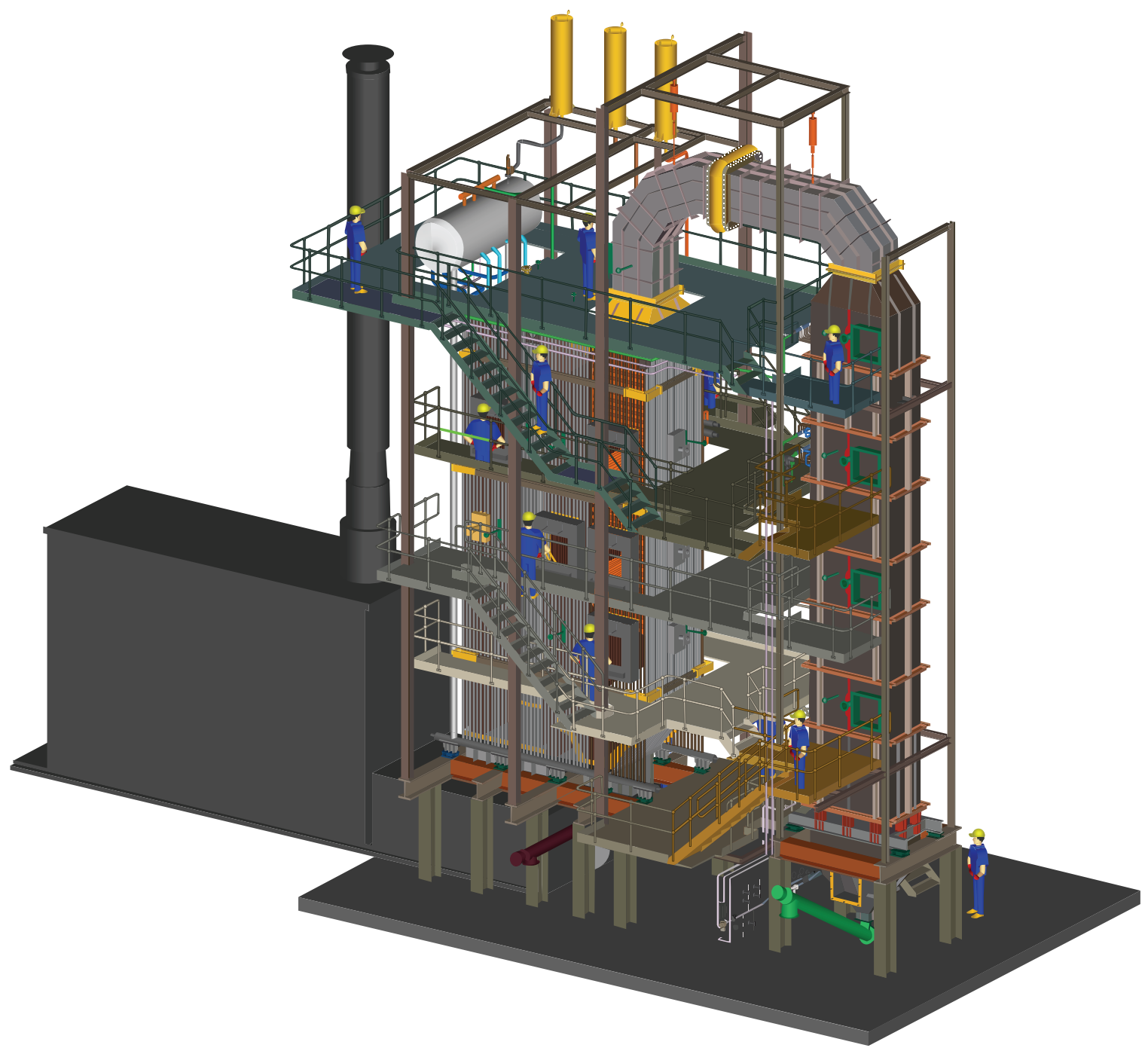

FIGURE 6: 3D-disposition of biomass incineration power plant "Milano."

the deformations of membrane wall and equivalent plate (thickness $h$ ), with the equivalent bending load

$$
\begin{gathered}
E_{b, 1}=\frac{E}{k \cdot h^{3}} \cdot\left[\frac{3 \cdot \pi}{16} \cdot\left(D^{4}-(D-2 \cdot \delta)^{4}\right)+(k-D) \cdot t^{3}\right], \\
E_{b, 2}=E \cdot\left(\frac{t}{h}\right)^{3} \cdot \frac{(n \cdot k)^{4}}{\sum_{i=1}^{n}(i \cdot k)^{4}-(i \cdot k-b)^{4}}, \\
G_{b, 12} \approx \frac{\sqrt{E_{b, 1} \cdot E_{b, 2}}}{2 \cdot\left(1+\sqrt{\nu_{b, 12} \cdot v_{b, 21}}\right)}, \\
v_{b, 21}=v_{b, 12} \cdot \frac{E_{b, 2}}{E_{b, 1}},
\end{gathered}
$$

where $n$ is number of pipes in the membrane wall and $v_{b, 12}=$ $v$ is Poisson's factor for the isotropic material of membrane wall. After the homogenization of steam boiler membrane wall, the stiffness matrix of shell element can be calculated according to the expression

$$
\mathbf{k}=\int_{A} \mathbf{B}^{T} \mathbf{D B} d A,
$$

where $A$ is surface of shell element and $\mathbf{B}$ is operator of boundary magnitude.

\section{Calculation of Reactions in the Steam Boiler Supports for a Real Model of Membrane Wall Geometry, for the Membrane Walls Approximated by the Equivalent Orthotropic Plate, and for the Ideal Rigid Model of Boiler Geometry}

The finite element method using Abaqus 6.9-3 will be applied for the calculation of reactions in the supports. The real geometry of membrane walls (Figure 4) and the membrane walls approximated as the equivalent orthotropic plate (Figure 5) 


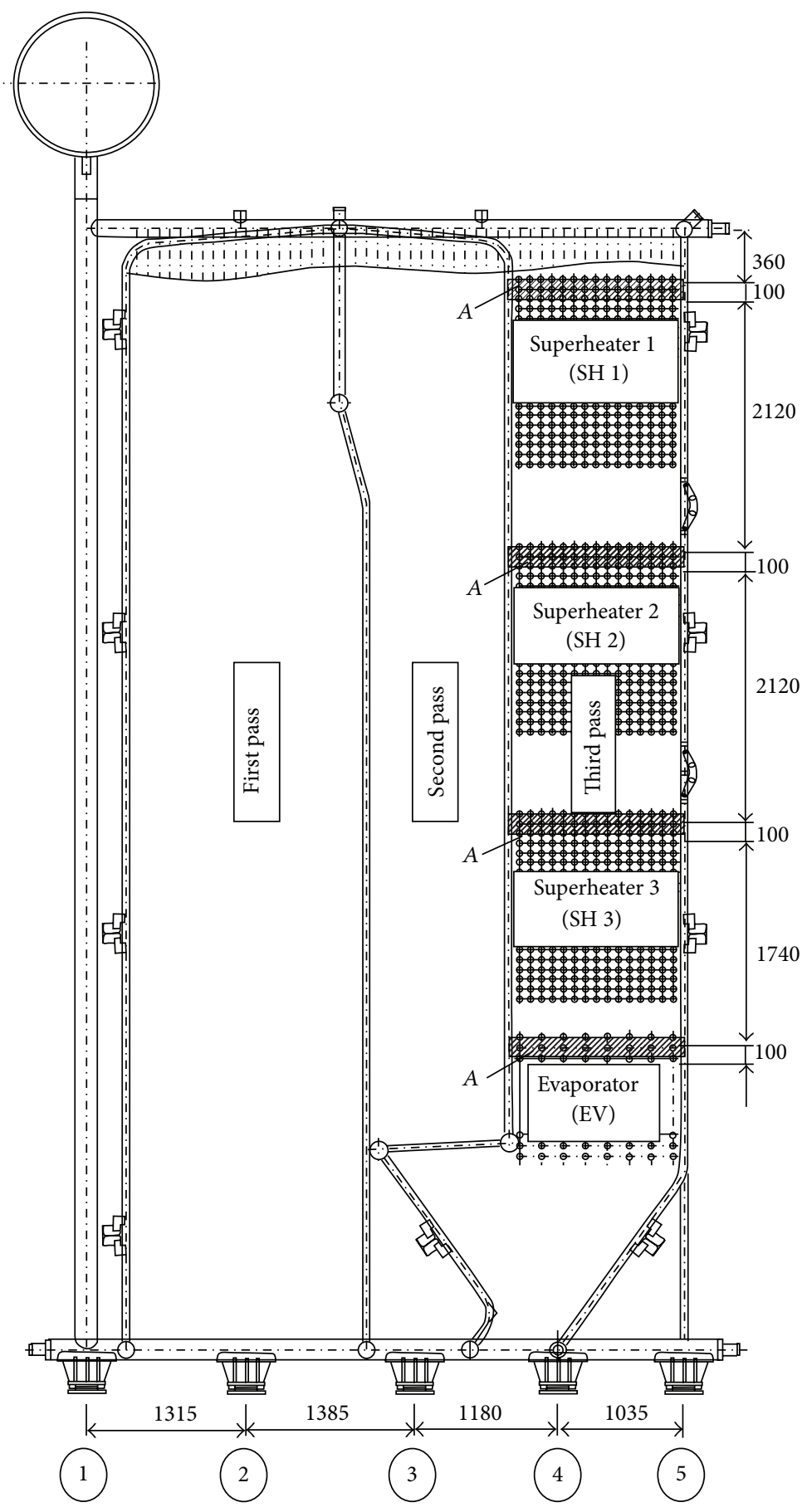

Figure 7: Position of boiler supports and heat exchangers (dimensions are in $\mathrm{mm}$ ).

will be discretized by a four-node doubly curved thin shell element using the reduced integration with hourglass control. The finite element has the codename S4R5 and it is applied for small deformations and has five degrees of freedom per node.

The load of the mass of boiler structure will be taken into consideration for the calculation of reactions in the supports of "Milano" steam boiler (Figure 6). Other loads, such as the mass of working fluid, the fouling mass that is deposited on the heating surfaces during the combustion process, the mass of refractory, and the mass of insulation, will not be considered here. Pipe material of membrane walls is P235GH, material of membrane tape and buckstays is S235JRG2, and material of chambers is $16 \mathrm{Mo}$. All three steels belong to the group of low-carbon steels with $\leq 0.3 \%$ carbon. Since the boiler membrane walls are evaporator heating surfaces, the calculation temperature is $\vartheta=275^{\circ} \mathrm{C}$. Assuming that the mechanical properties of boiler structure are isotropic, [36] the modulus of elasticity for all three materials is 
TABLE 1: List of positions according to Figure 4.

\begin{tabular}{|c|c|c|c|c|c|}
\hline Pos. & Type & Dimensions & Pos. & Type & Dimensions \\
\hline 1 & Shell and end of drum & $\phi 1200 \times 35 \mathrm{~mm}$ & 14 & $\begin{array}{l}\text { Collector header of } \\
\text { side wall }\end{array}$ & $\phi 139.7 \times 12.5 \mathrm{~mm}$ \\
\hline 2 & Downcomers & $\phi 168.3 \times 16 \mathrm{~mm}$ & 15 & $\begin{array}{l}\text { Collector header of } \\
\text { rear wall of third pass }\end{array}$ & $\phi 139.7 \times 12.5 \mathrm{~mm}$ \\
\hline 3 & Connecting pipe & $\phi 88.9 \times 8.8 \mathrm{~mm}$ & 16 & $\begin{array}{l}\text { Side wall of second } \\
\text { pass }\end{array}$ & $\begin{array}{c}\text { Pipe: } \phi 57 \times 4 \mathrm{~mm} \\
\text { Tape: } t=6 \mathrm{~mm} \\
\text { Step: } k=90 \mathrm{~mm} \\
\text { Number of pipes: } \\
\quad n=12\end{array}$ \\
\hline 4 & $\begin{array}{l}\text { Collector header of } \\
\text { rear wall of first pass }\end{array}$ & $\phi 139.7 \times 12.5 \mathrm{~mm}$ & 17 & $\begin{array}{c}\text { Rear wall of second } \\
\text { pass }\end{array}$ & $\begin{array}{c}\text { Pipe: } \phi 57 \times 4 \mathrm{~mm} \\
\text { Tape: } t=6 \mathrm{~mm} \\
\text { Step: } k=90 \mathrm{~mm} \\
\text { Number of pipes: } \\
n=23\end{array}$ \\
\hline 5 & Front wall of first pass & $\begin{array}{c}\text { Pipe: } \phi 57 \times 4 \mathrm{~mm} \\
\text { Tape: } t=6 \mathrm{~mm} \\
\text { Step: } k=90 \mathrm{~mm} \\
\text { Number of pipes: } \\
n=23\end{array}$ & 18 & Side wall of third pass & $\begin{array}{c}\text { Pipe: } \phi 48.3 \times 4.5 \mathrm{~mm} \\
\text { Tape: } t=6 \mathrm{~mm} \\
\text { Step: } k=90 \mathrm{~mm} \\
\text { Number of pipes: } \\
n=15\end{array}$ \\
\hline 6 & Side wall of first pass & $\begin{array}{c}\text { Pipe: } \phi 57 \times 4 \mathrm{~mm} \\
\text { Tape: } t=6 \mathrm{~mm} \\
\text { Step: } k=90 \mathrm{~mm} \\
\text { Number of pipes: } \\
n=21\end{array}$ & 19 & Rear wall of third pass & $\begin{array}{c}\text { Pipe: } \phi 57 \times 4 \mathrm{~mm} \\
\text { Tape: } t=6 \mathrm{~mm} \\
\text { Step: } k=90 \mathrm{~mm} \\
\text { Number of pipes: } \\
n=23\end{array}$ \\
\hline 7 & Rear wall of first pass & $\begin{array}{c}\text { Pipe: } \phi 57 \times 4 \mathrm{~mm} \\
\text { Tape: } t=6 \mathrm{~mm} \\
\text { Step: } k=90 \mathrm{~mm} \\
\text { Number of pipes: } \\
n=23\end{array}$ & 20 & Buckstays & HE-B120 \\
\hline 8 & $\begin{array}{l}\text { Collector header of } \\
\text { wall of hopper }\end{array}$ & $\phi 139.7 \times 12.5 \mathrm{~mm}$ & 21 & $\begin{array}{l}\text { Distributor header of } \\
\text { rear wall of second } \\
\text { pass }\end{array}$ & $\phi 139.7 \times 12.5 \mathrm{~mm}$ \\
\hline 9 & Connecting pipes & $\phi 48.3 \times 4 \mathrm{~mm}$ & 22 & Wall of hopper & $\begin{array}{c}\text { Pipe: } \phi 57 \times 4 \mathrm{~mm} \\
\text { Tape: } t=6 \mathrm{~mm} \\
\text { Step: } k=90 \mathrm{~mm} \\
\text { Number of pipes: } \\
n=23\end{array}$ \\
\hline 10 & $\begin{array}{c}\text { Distributor header of } \\
\text { side wall }\end{array}$ & $\phi 168.3 \times 20 \mathrm{~mm}$ & 23 & $\begin{array}{l}\text { Distributor header of } \\
\text { rear wall of first pass }\end{array}$ & $\phi 139.7 \times 12.5 \mathrm{~mm}$ \\
\hline 11 & $\begin{array}{c}\text { Distributor header of } \\
\text { front wall }\end{array}$ & $\phi 139.7 \times 12.5 \mathrm{~mm}$ & 24 & $\begin{array}{c}\text { Distributor header of } \\
\text { wall of hopper }\end{array}$ & $\phi 139.7 \times 12.5 \mathrm{~mm}$ \\
\hline 12 & $\begin{array}{l}\text { Collector header of } \\
\text { front and rear wall of } \\
\text { second pass }\end{array}$ & $\phi 139.7 \times 12.5 \mathrm{~mm}$ & 25 & $\begin{array}{l}\text { Distributor header of } \\
\text { rear wall of third pass }\end{array}$ & $\phi 139.7 \times 12.5 \mathrm{~mm}$ \\
\hline 13 & $\begin{array}{l}\text { Side wall in transition } \\
\text { zone }\end{array}$ & $\begin{array}{c}\text { Pipe: } \phi 57 \times 4 \mathrm{~mm} \\
\text { Tape: } t=6 \mathrm{~mm} \\
\text { Step: } k=90 \mathrm{~mm} \\
\text { Number of pipes: } \\
n=34\end{array}$ & & & \\
\hline
\end{tabular}

approximately equal and amounts to $E=187.12 \mathrm{GPa}$. For the value of Poisson's factor, $v=0.3$ is used.

Due to the single boiler symmetry, for the calculation using the finite element method, it is sufficient to model only one-half of the boiler geometry (Figures 4 and 5). The boiler is supported by ten supports, five on the distributor chamber of the left side wall and five on the distributor chamber of the right side wall (Figure 7). In the third pass of the boiler, the heat exchangers were installed, that is, one evaporator and three superheaters. The heat exchangers were supported on the side walls of the third pass. Due to the weight of heat exchangers, the load of the left and right side wall of the third 
TABLE 2: Masses of constituent structural elements for half geometry of "Milano" boiler.

\begin{tabular}{lccccccccc}
\hline Pos. & Mass, kg & Pos. & Mass, kg & Pos. & Mass, kg & Pos. & Mass, kg & Pos. & Mass, kg \\
\hline 1 & 1967 & 7 & 639 & 13 & 315 & 19 & 786 & 25 & 43 \\
2 & 595 & 8 & 43 & 14 & 197 & 20 & 668 & SH1 & 1185 \\
3 & 23 & 9 & 17 & 15 & 43 & 21 & 43 & SH2 \\
4 & 43 & 10 & 402 & 16 & 702 & 22 & 157 & SH3 & 527 \\
5 & 893 & 11 & 43 & 17 & 721 & 23 & 43 & EV & 53 \\
6 & 1184 & 12 & 43 & 18 & 1018 & 24 & 43 & \\
\hline
\end{tabular}

TABLE 3: Elasticity constants and wall thickness of equivalent orthotropic plate for membrane walls of "Milano" boiler.

\begin{tabular}{|c|c|c|c|c|c|c|c|c|c|}
\hline $\begin{array}{l}\text { Membrane wall } \\
\text { (position) }\end{array}$ & $\begin{array}{c}h, \\
\mathrm{~mm}\end{array}$ & $\begin{array}{l}E_{m, 1} \\
\mathrm{GPa}\end{array}$ & $\begin{array}{l}E_{m, 2}, \\
\mathrm{GPa} \\
\end{array}$ & $\begin{array}{c}G_{m, 12}, \\
\text { GPa }\end{array}$ & $v_{m, 21}$ & $\begin{array}{l}E_{b, 1} \\
\mathrm{GPa} \\
\end{array}$ & $\begin{array}{l}E_{b, 2} \\
\mathrm{GPa}\end{array}$ & $\begin{array}{c}G_{b, 12} \\
\mathrm{GPa}\end{array}$ & $v_{b, 21}$ \\
\hline $5,7,17,19,22$ & 23.48 & 76.492 & 1.367 & 4.915 & 0.005361 & 454.159 & 8.064 & 29.095 & 0.005327 \\
\hline 6 & 23.48 & 76.492 & 1.367 & 4.915 & 0.005361 & 454.159 & 8.023 & 29.025 & 0.005300 \\
\hline 13 & 23.48 & 76.492 & 1.367 & 4.915 & 0.005361 & 454.159 & 8.203 & 29.336 & 0.005419 \\
\hline 16 & 23.48 & 76.492 & 1.367 & 4.915 & 0.005361 & 454.159 & 7.690 & 28.439 & 0.005080 \\
\hline 18 & 20.40 & 88.592 & 3.880 & 8.722 & 0.013138 & 442.956 & 9.583 & 31.199 & 0.006490 \\
\hline
\end{tabular}

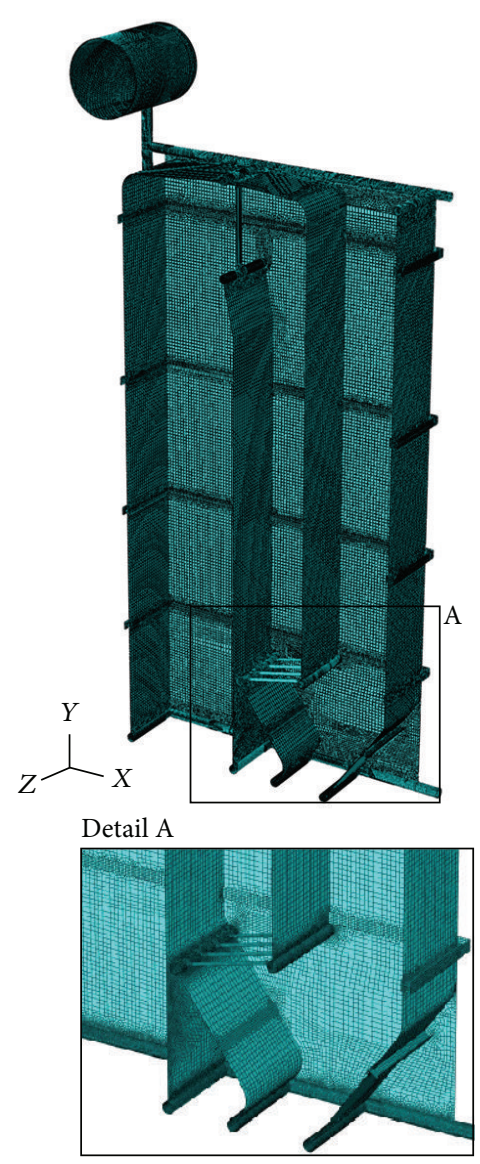

FIGURE 8: Finite element mesh-calculation model APPROX.

pass is identical. For the calculation of reactions in the boiler supports, half of the weight of individual heat exchanger will be used as the equivalent tangential surface pressure on the side wall of the third pass. This pressure is applied on surface
TABLE 4: Members of elasticity matrix of equivalent orthotropic plate for membrane walls of "Milano" boiler for membrane stiffness.

\begin{tabular}{lcccc}
\hline $\begin{array}{l}\text { Membrane wall } \\
\text { (position) }\end{array}$ & $\begin{array}{c}A_{11}, \\
\mathrm{~N} / \mathrm{mm}\end{array}$ & $\begin{array}{c}A_{12}, \\
\mathrm{~N} / \mathrm{mm}\end{array}$ & $\begin{array}{c}A_{22}, \\
\mathrm{~N} / \mathrm{mm}\end{array}$ & $\begin{array}{c}A_{33}, \\
\mathrm{~N} / \mathrm{mm}\end{array}$ \\
\hline $5,6,7,13,16,17$, & 1799282 & 9646 & 32152 & 115438 \\
19,22 & 1814749 & 23843 & 79476 & 177966 \\
18 & &
\end{tabular}

TABLE 5: Members of elasticity matrix of equivalent orthotropic plate for membrane walls of "Milano" boiler for bending stiffness.

\begin{tabular}{lcccc}
\hline $\begin{array}{l}\text { Membrane wall } \\
\text { (position) }\end{array}$ & $\begin{array}{c}D_{11}, \\
\mathrm{~N} \cdot \mathrm{mm}\end{array}$ & $\begin{array}{c}D_{12}, \\
\mathrm{~N} \cdot \mathrm{mm}\end{array}$ & $\begin{array}{c}D_{22}, \\
\mathrm{~N} \cdot \mathrm{mm}\end{array}$ & $\begin{array}{c}D_{33}, \\
\mathrm{~N} \cdot \mathrm{mm}\end{array}$ \\
\hline $5,7,17,19,22$ & 491000497 & 2615341 & 8717804 & 31404889 \\
6 & 490996567 & 2602240 & 8674134 & 31329272 \\
13 & 491014120 & 2660750 & 8869166 & 31665404 \\
16 & 490964096 & 2494004 & 8313348 & 30696524 \\
18 & 314156438 & 2038906 & 6796354 & 22084218 \\
\hline
\end{tabular}

TABLE 6: Reactions in the boiler supports for the influence of total mass.

\begin{tabular}{lccccc}
\hline $\begin{array}{l}\text { Reactions in } \\
\text { boiler supports }\end{array}$ & $F_{R 1}, \mathrm{~N}$ & $F_{R 2}, \mathrm{~N}$ & $F_{R 3}, \mathrm{~N}$ & $F_{R 4}, \mathrm{~N}$ & $F_{R 5}, \mathrm{~N}$ \\
\hline REAL & 22748 & 27020 & 32657 & 38515 & 12676 \\
APPROX & 24183 & 25992 & 31015 & 40026 & 12499 \\
RIGID & 27234 & 22608 & 31088 & 36609 & 16077 \\
$\Delta_{A}, \%$ & 6.31 & -3.80 & -5.03 & 3.92 & -1.40 \\
$\Delta_{K}, \%$ & 19.72 & -16.33 & -4.80 & -4.95 & 26.83 \\
\hline
\end{tabular}

A of membrane wall on which the carriers of heat exchangers are welded (Figure 7). Bending of the side membrane walls of the third pass, due to the load of heat exchangers, was not taken into consideration. 
TABLE 7: Reactions in the boiler supports for the influence of mass of boiler without the mass of heat exchangers.

\begin{tabular}{|c|c|c|c|c|c|}
\hline $\begin{array}{l}\text { Reactions in boiler supports } \\
\text { without the mass of heat exchangers }\end{array}$ & $F_{R 1}, \mathrm{~N}$ & $F_{R 2}, \mathrm{~N}$ & $F_{R 3}, \mathrm{~N}$ & $F_{R 4}, \mathrm{~N}$ & $F_{R 5}, \mathrm{~N}$ \\
\hline REAL & 24329 & 29007 & 24633 & 21190 & 5521 \\
\hline APPROX & 25790 & 27681 & 23752 & 21822 & 5574 \\
\hline RIGID & 27397 & 21905 & 34552 & 10957 & 9869 \\
\hline$\Delta_{A}, \%$ & 6.01 & -4.57 & -3.58 & 2.98 & 0.96 \\
\hline$\Delta_{K}, \%$ & 12.61 & -24.48 & 40.27 & -48.29 & 78.75 \\
\hline
\end{tabular}

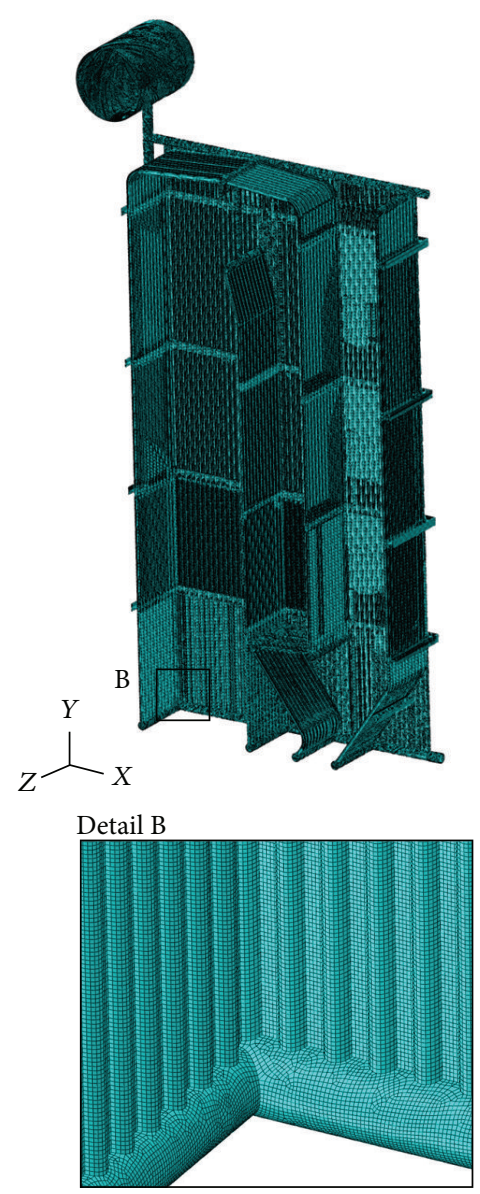

FIGURE 9: Finite element mesh-calculation model REAL.

The masses of individual structural elements of boiler, marked according to Figures 4 and 7 and Table 1, are given in Table 2. The inhomogeneity of material of boiler structure will not be taken into consideration here. It is assumed that the geometry of boiler is ideal, without the tolerances of production and assembly, as well as the tolerances of semifinished rolled products built into the boiler. It is assumed that the mechanical properties of material of boiler structure are isotropic, that is, that anisotropy of the welded joints and semifinished rolled products does not influence significantly the reactions in the boiler supports.

The mass of half of boiler without the heat exchangers is $m^{\prime}=10671 \mathrm{~kg}$, and with the heat exchangers it is $m=$ $13621 \mathrm{~kg}$. The membrane walls of "Milano" boiler are made with the step of $90 \mathrm{~mm}$. Two dimensions of the cross-section of pipe $(\phi 57 \times 4 \mathrm{~mm}$ and $\phi 48.3 \times 4.5 \mathrm{~mm})$ are applied, as well as the membrane tape (thickness, $6 \mathrm{~mm}$ ). For the boiler membrane walls, it is possible to calculate the elasticity constants of equivalent orthotropic plate (Table 3) according to expressions (2) and (7). The members of elasticity matrix (Tables 4 and 5), which will be applied to the finite element of equivalent orthotropic plate, will be calculated according to expressions (3) and (4).

In this paper, the results of six different calculations of reactions in the supports of "Milano" boiler will be presented: the calculation of real geometry of boiler (REAL) discretized by the shell finite element, the calculation with the approximation of membrane walls as the plate/shell of equivalent stiffness (APPROX), and the calculation where the boiler is considered as a rigid body (RIGID). Each calculation is made with the load of the mass of boiler, with and without the mass of heat exchangers.

The calculation model for the real geometry of boiler consisted of 18943590 variables that include the degrees of freedom and Lagrange multipliers, and for the approximated geometry of boiler membrane walls as the plate/shell of equivalent stiffness, the calculation model consisted of 1619526 variables (degrees of freedom and Lagrange multipliers). In both cases, 4-node finite element S4R5 was predominantly used, and an extremely triangular element was created by the collapse of one node of 4-node element S4R5 (Figures 8 and 9).

The reaction forces in the supports for the influence of total mass of boiler are given in Table 6 , and the reaction forces for the influence of mass of boiler without the mass of heat exchangers are given in Table 7. The reaction forces in the boiler supports are denoted according to Figure 7. In Tables 6 and 7, the deviations of reaction forces for calculation APPROX (compared to calculation REAL) were calculated, and the deviation was expressed as a percentage and marked as $\Delta_{A}$. In the same way, the deviation of reaction forces for calculation RIGID (compared to calculation REAL) was calculated, and it was expressed as a percentage and marked as $\Delta_{K}$. The deviations were calculated according to the following expressions:

$$
\begin{gathered}
\Delta_{A}=\left(\frac{F_{\mathrm{Ri}}(\mathrm{APPROX})}{F_{\mathrm{Ri}}(\mathrm{REAL})}-1\right) \cdot 100, \%, \\
\Delta_{K}=\left(\frac{F_{\mathrm{Ri}}(\mathrm{RIGID})}{F_{\mathrm{Ri}}(\mathrm{REAL})}-1\right) \cdot 100, \% .
\end{gathered}
$$




\section{Conclusion}

The investigation of the influence of approximation of steam boiler membrane walls, using the equivalent orthotropic plate for the calculation of reactions in the boiler supports, is presented in this paper. The expressions for the elasticity constants that have been published in previous papers [3032] were applied.

(i) The reactions in the boiler supports were calculated with the assumption that the structure of boiler is ideally rigid.

(ii) The calculations were carried out for the load of the mass of boiler, with and without the mass of heat exchangers in the third pass of boiler.

(iii) The number of variables for the calculation model REAL was more than 11 times higher than for the calculation model APPROX. Therefore, the calculation of node values of model REAL lasted for $1 \mathrm{~h}$, $23 \mathrm{~min}$ and $50 \mathrm{~s}$, and for the model APPROX $1 \mathrm{~min}$ and $56 \mathrm{~s}$. The calculation was carried out on a PC with CPU Intel(R) Core (TM) i7, 24 GB RAM, and 64-bit operating system.

(iv) The deviations of results for the reactions in the supports for the calculation APPROX, compared to the calculation REAL, are max. $6.31 \%$ for the load of the total mass of boiler and $6.01 \%$ for the load without the mass of heat exchangers.

(v) The deviations of results for the calculation RIGID, compared to the calculation REAL, are $78.75 \%$ for the load without the mass of heat exchangers.

(vi) If the results of calculation REAL are accepted as approximately accurate, then it can be concluded that the application of calculation model APPROX is acceptable for practical use. Due to the huge error, the calculation model RIGID is not recommended for practical use.

(vii) Using the method of equivalent stiffness of membrane wall, more accurate results of calculation could be acquired if, when calculating the modulus of elasticity $E_{b, 2}$, the membrane pipe would be observed as a solid body, and not as an ideal rigid body [32].

(viii) Additional improvements could be achieved by taking into consideration the transverse shear stiffness.

\section{Conflict of Interests}

The authors declare that there is no conflict of interests regarding the publication of this paper.

\section{Acknowledgment}

The authors would like to thank PLANUM d.o.o. from Slavonski Brod in Croatia for usage of technical data which were needed for this research.

\section{References}

[1] V. Milošević-Mitić, B. Gaćeša, N. Anđelić, and T. Maneski, "Numerical calculation of the water-tube boiler using finite element of the orthotropic plate," Structural Integrity and Life, vol. 12, no. 3, pp. 185-190, 2012.

[2] M. T. Huber, "Die grundlagen einer rationellen berechnung der kreuzweise bewehrten eisenbetonplatten," Zeitschrift des Österreichischen Ingenieur- und Architekten-Vereins, vol. 66, pp. 557-564, 1914.

[3] M. T. Huber, "Die Theorie der kreuzweise bewehrten Eisenbeton-platten nebst Anwendungen auf mehrere bautechnisch wichtige Aufgaben über rechteckige Platten," Bauingenieur, vol. 4, pp. 354-360, 1923.

[4] M. T. Huber, Probleme der Statik Technisch Wichtiger Orthotroper Platten, Nakkadem Akadenji Nauk Technicznych, Warszawa, Poland, 1929.

[5] W. Flügge, "Die Stabilität der Kreiszylinderschale," IngenieurArchiv, vol. 3, no. 5, pp. 463-506, 1932.

[6] A. van der Neut, "The general instability of stiffened cylindrical shells under axial compression," Report S. 314, National Luchtvaartlaboratorium, 1947.

[7] F. A. Dale, R. C. T. Smith et al., "Grid sandwich panels in compression," Report ACA-16, Australian Council for Aeronautics, 1945.

[8] C. B. Smith, T. B. Heebink, and C. B. Norris, "The effective stiffness of a stiffener attached to a flat plywood plate," Report 1557, U. S. Department of Agriculture, Forest Products Laboratory, 1946.

[9] A. Pflüger, "Zum Beulproblem der anisotropen Rechteckplatte," Ingenieur-Archiv, vol. 16, no. 2, pp. 111-120, 1947.

[10] A. Gomza and P. Seide, "Minimum-weight design of simply supported transversely stiffened plates under compression," NACA TN 1710, 1948.

[11] C. Libove and R. E. Hubka, "Elastic constants for corrugatedcore sandwich plates," NACA TN 2289, 1951.

[12] C. Libove and S. B. Batdorf, "A general small-deflection theory for flat sandwich plates," NACA Report 899, 1948.

[13] E. Reissner, "On small bending and stretching of sandwich-type shells," International Journal of Solids and Structures, vol. 13, no. 12, pp. 1293-1300, 1977.

[14] M. Stein and J. Mayers, "A small-deflection theory for curved sandwich plates," NACA Report 1008, 1951.

[15] N. J. Huffington Jr., "Theoretical determination of rigidity properties of orthogonally stiffened plates," Journal of Applied Mechanics, vol. 23, pp. 15-20, 1956.

[16] G. Gerard, "Minimum weight analysis of orthotropic plates under compressive loading," Journal of the Aeronautical Sciences, vol. 27, no. 1, pp. 21-26, 1960.

[17] M. Baruch and J. Singer, "Effect of eccentricity of stiffeners on the general instability of stiffened cylindrical shells under hydrostatic pressure," Journal of Mechanical Engineering Science, vol. 5, no. 1, pp. 23-27, 1963.

[18] R. J. Clifton, J. C. L. Chang, and T. Au, "Analysis of orthotropic plate bridges," ASCE Journal of the Structural Division, vol. 89, no. 5, pp. 133-171, 1963.

[19] W. J. Stroud, "Elastic constants for bending and twisting of corrugation-stiffened panels," NASA TR R 166, 1963.

[20] R. R. Meyer and R. J. Bellefante, "Fabrication and experimental evaluation of common domes having waffle-like stiffeningpart I-program development," Report SM 47742, Douglas Missile \& Space Systems Division, 1964. 
[21] T.-C. Soong, "Buckling of cylindrical shells with eccentric spiral-type stiffeners," AIAA Journal, vol. 7, no. 10, pp. 65-72, 1969.

[22] R. R. Meyer, "Comments on: buckling of cylindrical shells with eccentric spiral-type stiffeners," AIAA Journal, vol. 7, no. 10, p. 2047, 1969.

[23] T.-C. Soong, "Reply by author to R. R. Meyer," AIAA Journal, vol. 7, no. 10, pp. 2047-2048, 1969.

[24] F. Nishino, R. P. Pama, and S.-L. Lee, "Orthotropic plates with eccentric stiffeners," International Association of Bridge Structural Engineering, vol. 34, no. 2, pp. 117-129, 1974.

[25] W. L. Ko, "Elastic constants for superplastically formed/diffusion-bonded sandwich structures," in Proceedings of the AIAA/ASME/AHS 20th Structures, Structural Dynamics, and Materials Conference, AIAA paper 79-0756, 1979.

[26] W. L. Ko, "Elastic constants for superplastically formed/diffusion-bonded sandwich structures," AIAA Journal, vol. 18, no. 8, pp. 986-987, 1980.

[27] W. L. Ko, "Elastic stability of superplastically formed/diffusionbonded orthogonally corrugated core sandwich plates," in Proceedings of the AIAA/ASME/AHS 21st Structures, Structural Dynamics, and Materials Conference, AIAA paper 80-0683, 1980.

[28] N. Jaunky, N. F. Knight Jr., and D. R. Ambur, "Formulation of an improved smeared stiffener theory for buckling analysis of grid-stiffened composite panels," NASA TM 110162, 1995.

[29] N. Jaunky, F. Knight, and D. R. Ambur, "Formulation of an improved smeared stiffener theory for buckling analysis of gridstiffened composite panels," Composites B, vol. 27, pp. 519-526, 1996.

[30] J. Sertić, D. Kozak, D. Damjanović, and P. Konjatić, "Homogenization of steam boiler membrane wall," in Proceedings of 7 th International Congress of Croatian Society of Mechanics, Zadar, 2012.

[31] J. Sertić, I. Gelo, D. Kozak, D. Damjanović, and P. Konjetić, "Teoretical determination of elasticity constants for steam boiler membrane wall as the structurally ortotropic plate," in Proceeding of 4th International Scientific and Expert Conference of the International TEAM Society, Slavonski Brod, 2012.

[32] J. Sertić, I. Gelo, D. Kozak, D. Damjanović, and P. Konjatić, "Theoretical determination of elasticity constants for steam boiler membrane wall as the structurally orthotropic plate," Technical Gazette, vol. 20, no. 4, pp. 697-703, 2013.

[33] R. Solecki and R. J. Conant, Advanced Mechanics of Materials, Oxford University Press, Oxford, UK, 2003.

[34] E. Ventsel and T. Krauthammer, Thin Plates and Shells. Theory, Analysis and Applications, Marcel Dekker, Basel, Switzerland, 2001.

[35] V. V. Novozhilov, Thin Shell Theory, Noordhoff, Groningen, Germany, 1964.

[36] ASME B31.1, 1995. 

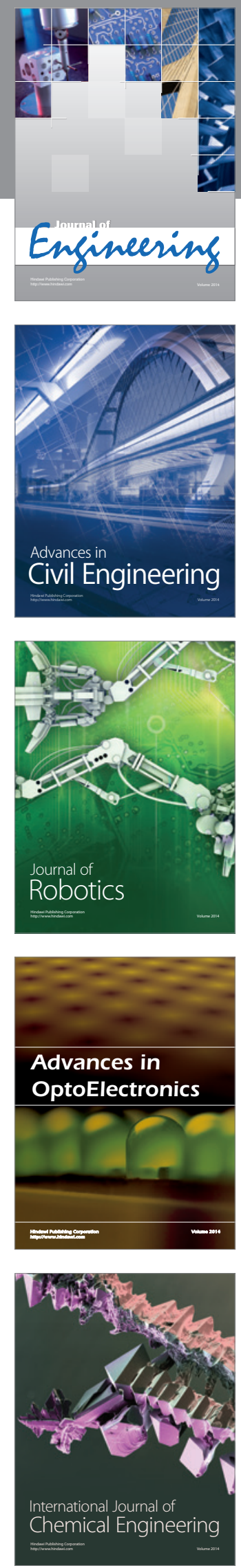

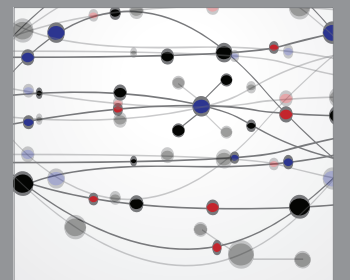

The Scientific World Journal
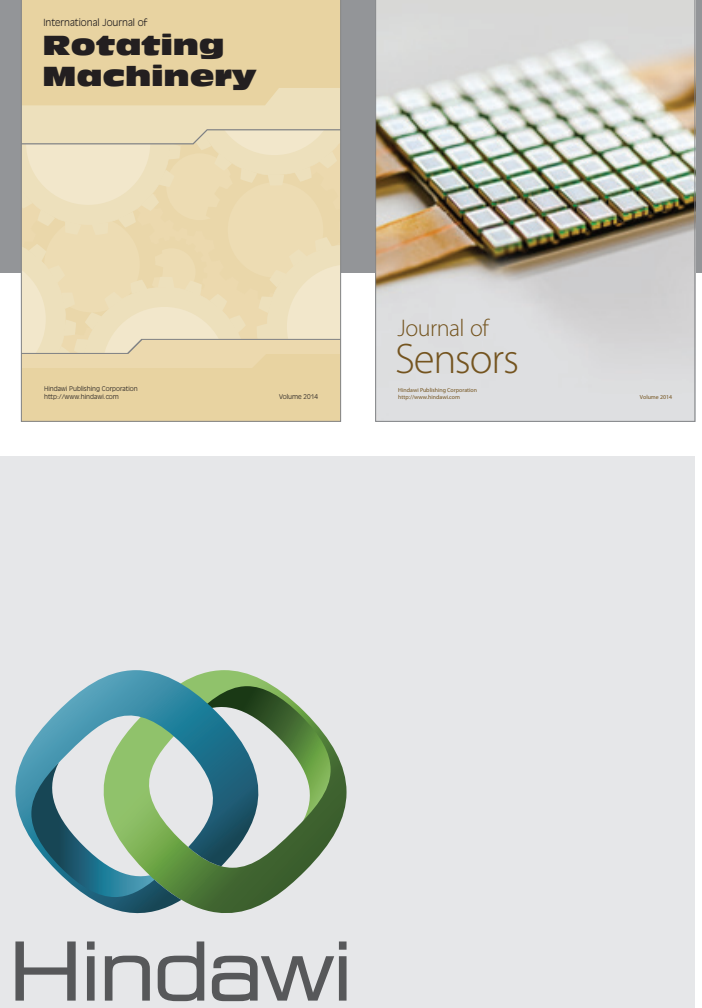

Submit your manuscripts at http://www.hindawi.com
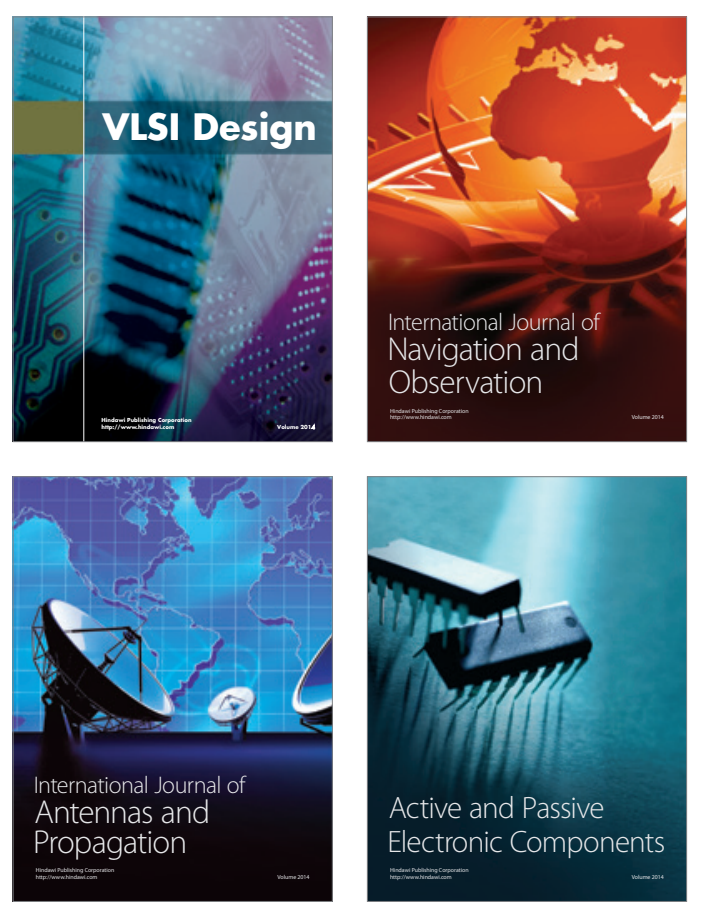
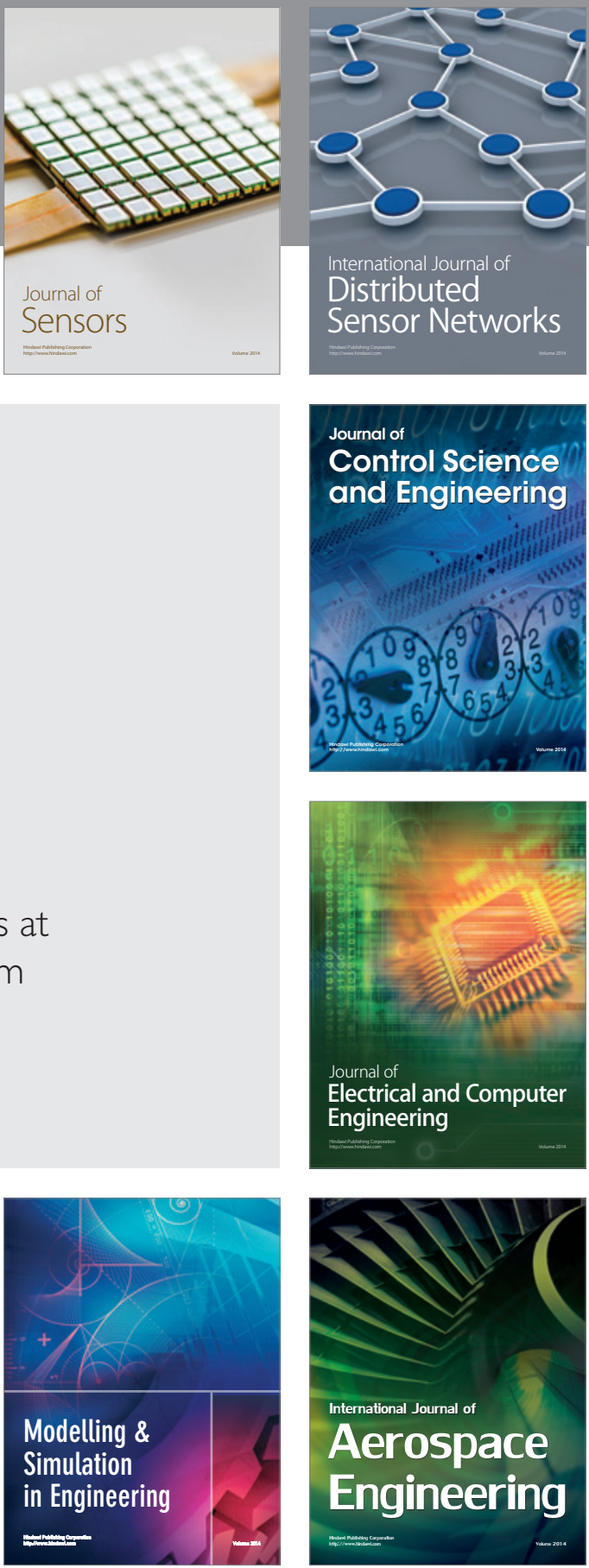

Journal of

Control Science

and Engineering
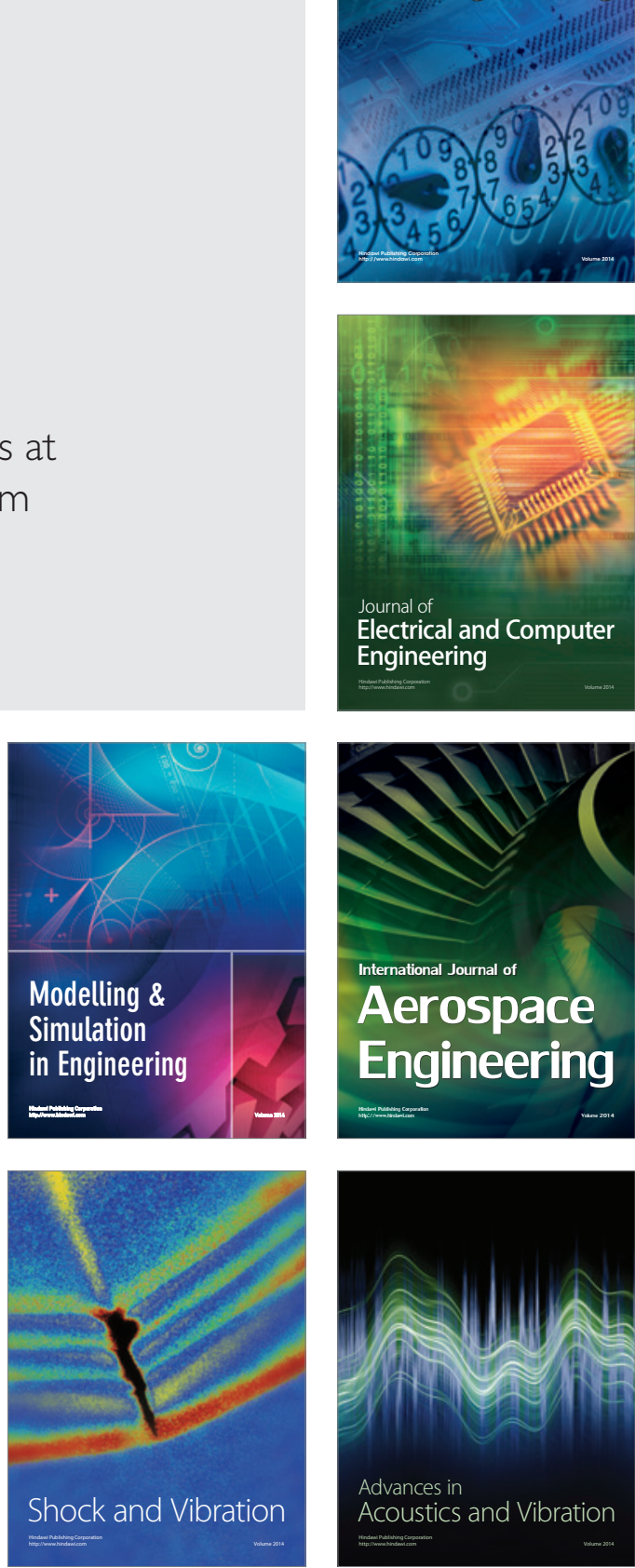